\title{
TELETRABALHO E COVID-19: DESAFIOS E PERSPECTIVAS PARA O MUNDO DO TRABALHO
}

\author{
Antônio Célio Martins Timbó Costa ${ }^{1}$
}

\section{Resumo:}

Além dos impactos na saúde, a pandemia da Covid-19 teve intensas repercussões na vida cotidiana das pessoas, tendo acarretado agravos sociais e econômicos incalculáveis. Emergem formas de precarização do trabalho humano, como o trabalho em plataformas digitais e o teletrabalho. O presente estudo pretende refletir sobre as repercussões da Covid-19 sobre o mundo do trabalho, buscando responder a seguinte questão: em que medida o teletrabalho, na realidade advinda da pandemia, contribuirá para o estabelecimento (ou não) de relações de trabalho mais humanas. Dado o caráter multifacetário do teletrabalho, o mesmo é analisado sob as perspectivas sociológica, administrativa, psicológica e jurídica.

Palavras-chave: Teletrabalho, Covid-19, Mundo do trabalho.

\section{TELEWORKING AND COVID-19: CHALLENGES AND PERSPECTIVES FOR THE WORLD OF WORK}

\begin{abstract}
:
In addition to the impacts on health, the Covid-19 pandemic had intense repercussions on people's daily lives, causing incalculable social and economic problems. Forms of precarious human work emerge, such as working on digital platforms and teleworking. This study aims to reflect on the repercussions of Covid-19 on the world of work, seeking to answer the following question: to what extent teleworking, in reality arising from the pandemic, will contribute to the establishment (or not) of more humane working relationships. Given the multifaceted nature of teleworking, it is analyzed from a sociological, administrative, psychological and legal perspective.
\end{abstract}

Keywords: Teleworking, Covid-19, World of work.

\section{Introdução}

A crise deflagrada pela Covid-19 — dado o seu caráter multissetorial — tem se caracterizado como o maior desafio contemporâneo. Diz-se que é comparável às duas guerras mundiais, à guerra fria e mesmo ao atentado terrorista às Torres Gêmeas do World Trade Center, nos EUA, em 2001. Nesse sentido, líderes mundiais da envergadura da chanceler

\footnotetext{
${ }^{1}$ Mestre em Processo e Direito ao Desenvolvimento pelo Centro Universitário Christus - UNICHRISTUS. Bacharel em Direito pela Universidade Federal do Ceará. Bacharel em Administração de Empresas pela Universidade Estadual do Ceará. Especialista em Direito Constitucional pela Universidade Cândido Mendes. Especialista em Direito e Processo do Trabalho pela Universidade Cândido Mendes. Especialista em Relações Humanas pela Universidade Vale do Acaraú. Juiz do Trabalho Substituto do Tribunal Regional do Trabalho da 7ạ Região. Endereço eletrônico: celiotimbo@gmail.com.
} 
alemã Angela Merkel afirmam que se vive uma crise global, sem precedentes, sendo talvez a maior crise global desde a Segunda Guerra Mundial (CARBAJOSA, 2020).

Afeta, a um só tempo, a economia, a saúde, a política, a organização produtiva, o mundo do trabalho, os arranjos familiares e mesmo a saúde mental de todos os habitantes do planeta, a um só tempo.

Vive-se sobre o signo do medo: medo da morte, medo do desemprego, medo da deterioração das condições sociais - o que poderia levar ao recrudescimento da violência urbana -, medo da terceira onda, medo do amanhã. Trata-se de um "Medo caótico generalizado" (SANTOS, 2020, p. 10).

Essa situação pode inclusive agravar quadros psiquiátricos pré-existentes e causar, em pessoas sãs, estresse e ansiedade (OLIVEIRA, 2020).

Por isso, a grande importância da temática, sendo certo que discorrer sobre mesma é um grande desafio. Nas palavras de Santos (2020, p. 13) "escrever sobre ela é pôr as nossas categorias e a nossa linguagem à beira do abismo". Isso porque o mundo pandêmico, nas palavras do citado autor, atribui "à realidade uma liberdade caótica” (Ibid.).

Diga-se que o mundo do trabalho - campo de abordagem do presente estudo - se viu frontalmente atingindo pela crise sanitária, sem precedentes. Empresas fecharam suas portas no mundo todo, ocasionando desemprego e, na melhor das hipóteses, estabelecendo novos cânones produtivos. Entre estes, há que se referir ao teletrabalho, que passará a compor, de forma decisiva, como ser verá nesse estudo, o repertório de prestação de labor no mundo pós-pandêmico.

Tal engenho, muitas vezes, tem intensificado a exploração humana, posto que os teletrabalhadores se viram em situação de disponibilidade absoluta às ordens do capital, para bem além da jornada diária que se costumava prestar no ambiente corporativo.

O presente trabalho pretende refletir sobre as repercussões da Covid-19 no mundo do trabalho. Nesse contexto, pretende-se demonstrar que o trabalho subordinado será executado, com muito mais ênfase na modalidade de teletrabalho, o que ocasionara, inclusive, a diminuição dos espaços físicos empresariais de prestação do labor, com o uso de espaços denominados de coworking. Espera-se também que haja ganhos ambientais, tendo em vista que haverá menos deslocamentos, menos consumo de energia e também menos produção de lixo empresarial.

Nesse novo cenário, pretende-se demonstrar que as seguintes características serão preponderantes nesse novo mundo do trabalho: (i) a hipertrofia dos meios digitais de controle do trabalho, estabelecendo-se muitas vezes um sistema opressivo de vigilância do trabalhador, o que pode resvalar no malferimento de seus direitos de personalidade; (ii) a superexploração da mão de obra através dos controles telemáticos; e (iii) o empobrecimento das relações interpessoais do trabalhador, prejudicando o sentimento de pertença coletiva e o reconhecimento do trabalhador como classe social.

Assim, o trabalho busca responder a seguinte questão: em que medida o teletrabalho, na realidade advinda da pandemia, contribuirá para o estabelecimento (ou não) de relações de trabalho mais humanas.

O trabalho pretende, em apertada síntese: (i) refletir sobre os impactos da Covid-19 no mundo do trabalho; (ii) conceituar teletrabalho, analisando sua incidência no período da 
pandemia; e (iii) analisar os aspectos sociológicos, administrativos, psicológicos e jurídicos referentes ao teletrabalho.

A metodologia utilizada se pautou nos seguintes aspectos: (i) pesquisa em matérias jornalísticas, dado o caráter bastante atual das questões tratadas; (ii) pesquisa bibliográfica, buscando-se, na melhor doutrina, fundamentos teóricos acerca do tema sobre investigação; e (iii) pesquisa documental, analisando-se acórdãos do Tribunal Superior do Trabalho e do Supremo Tribunal Federal sobre a problemática.

\section{Covid-19 e o mundo do trabalho}

A Covid-19, doença surgida na China, no final do ano passado, tem afligido de forma brutal e não antes vivenciada pelas atuais gerações, todo o mundo. Trata-se de uma emergência sanitária que assola, de forma alarmante, a grande maioria dos países, causando mortes, angústia e dor, tanto física, quanto psicológica.

A situação foi alçada ao epíteto de pandemia pela Organização Mundial de Saúde (OMS), em 11 de março de 2020, obrigando os países de todo o mundo a tomarem medidas de caráter urgente. Na oportunidade, Tedros Adhanom, Diretor-geral da OMS manifestou sua preocupação: "A OMS tem tratado da disseminação [do Covid-19] em uma escala de tempo muito curta, e estamos muito preocupados com os níveis alarmantes de contaminação e, também, de falta de ação [dos governos]" (BRASIL. MINISTÉRIO DA SAÚDE, 2020).

Além dos esperados impactos no mundo da saúde, a pandemia teve intensas repercussões na vida cotidiana das pessoas, tendo acarretado agravos sociais e econômicos incalculáveis. No plano político, houve embates relativos à competência dos entes federados - Congresso Nacional, Presidência da República, Supremo Tribunal Federal, Estados e Municípios - o que somente fez com que tardasse a necessária reação do poder público.

Do ponto de vista sanitário, restou evidenciado que o combate ao novo vírus passava por simples medidas de higiene básica, como lavar periodicamente as mãos. Também foi recomendado o uso de máscaras e a adoção do chamado isolamento social (SECRETARIA DE SAÚDE DO ESTADO DO CEARÁ, 2020).

Ainda quanto ao distanciamento social, Estados e Municípios, através de atos normativos, decretaram medidas cabíveis, inclusive o chamado lockdown, que se dá quando as pessoas são obrigadas a permanecer em suas residências, somente se autorizando a saída daqueles envolvidos em atividades de caráter essencial (QUINTELA, 2020).

O mundo produtivo se viu obrigado a fazer uma intensa atualização nos sistemas de comunicação e informações, a fim de permitir que as pessoas pudessem trabalhar de forma remota, onde fosse possível, de forma a não se parar o mundo produtivo, o serviço público e a economia do país.

Sobre o teletrabalho, Beck (1999, p. 43), sociólogo alemão, pontua:

Dissolve-se uma premissa aparentemente imprescindível do sistema de trabalho das sociedades industriais: a necessidade de se trabalhar conjuntamente num mesmo lugar para produzir bens ou serviços perdeu sua validade. Postos de trabalho podem ser exportados, e no entanto os empregados podem "cooperar" transnacional ou até transcontinentalmente, 
ou mesmo oferecer serviços em "contato direto" com os consumidores ou receptores.

A princípio, ressalte-se que, dada a natureza exígua do presente trabalho, não se investigará as diferenças propostas na doutrina entre teletrabalho, home office e trabalho a distância, adotando-se o termo teletrabalho, posto que o mesmo fora consagrado pela legislação brasileira ${ }^{2}$.

Nesse sentido, nos termos do art. 75-B, caput, da Consolidação das Leis do Trabalho CLT, na redação inserta pela Reforma Trabalhista de 2017, "considera-se teletrabalho a prestação de serviços preponderantemente fora das dependências do empregador, com a utilização de tecnologias de informação e de comunicação que, por sua natureza, não se constituam como trabalho externo" (BRASIL, 1943, on-line).

Diga-se que, no teletrabalho, há aspectos intrínsecos que vão além simplesmente do trabalho fora das dependências da empresa" (STÜRMER; FINCATO, 2020). Com efeito, nessa forma de labor, faz-se necessária "a presença obrigatória da tecnologia da comunicação e informação, quer como ferramenta de trabalho, quer como mediadora da distância relacional, ou até como próprio espaço (virtual) de trabalho“ (Ibid., p. 2).

Assinale-se que a expressão trabalho remoto aparece, nos achados a que se teve acesso, como sinônimo de teletrabalho, passando a ser também utilizada.

Interessante observar que o teletrabalho tem aspecto interdisciplinar, indo bem além da seara jurídica. Com efeito, o instituto se relaciona a diversos ramos do conhecimento, conforme se analisará a seguir.

\section{Teletrabalho: aspectos sociológicos}

Segundo dados também da PNAD Covid-19, no Brasil, quando da realização da pesquisa, 7,8 milhões de pessoas realizavam trabalho remoto. Interessante observar que o nível de instrução com a maior participação de pessoas em trabalho remoto foi o "Superior completo ou Pós-graduação", com 28,3\%. Ressalte-se que no nível educacional "Sem instrução ao Ensino Fundamental" somente há $0,3 \%$ em trabalho remoto (BRASIL. INSTITUTO BRASILEIRO DE GEOGRAFIA E ESTATÍSTICA, 2020).

Nesse sentido, matéria da Folha de São Paulo alerta para o fato do teletrabalho, nesse período de pandemia, acentuar desigualdades. A matéria cita Fábio Senne - do Núcleo de Informação e Coordenação do Ponto BR (NIC.br): "A fata de conexão com a tecnologia limita o acesso de muitas pessoas às formas de trabalho remoto que ganham impulso na pandemia, especialmente as mais pobres" (BALTHAZAR, 2020, on-line).

Entende-se que o teletrabalho somente se desenvolverá com o avanço dos meios telemáticos, que possibilitem a conexão das pessoas. Isso somente poderá se dar dentro de

\footnotetext{
${ }^{2}$ É bem didática a solução proposta por Gilberto Stümer e Denise Fincato, segundo a qual teletrabalho seria um tipo do gênero trabalho à distância, ao passo que teletrabalho em domicílio é tipo do gênero teletrabalho. Os autores concluem, assim que "[...] não é correto utilizar como sinônimo de teletrabalho quer a expressão trabalho à distância, quer trabalho em domicílio (e sua variante home office)" (STÜRMER; FINCATO, 2020).
} 
uma sociedade que dê prioridade aos avanços tecnológicos. Surgirá, assim, “[...] um novo formato de relações pessoais e profissionais, tendo em vista a existência de uma sociedade extremamente conectada através das redes sociais, fato esse que propicia que as equipes de trabalho sejam distribuídas não somente sob o regime presencial como também à distância“" (FELIPPE, 2018, p. 112). Esses novos profissionais desembocarão inexoravelmente na prestação de labor de forma remota.

Em pesquisa aplicada a 906 teletrabalhadores, por pesquisadores vinculados à Universidade Federal do Paraná, com abrangência nacional, no período de 5 a 17 de maio de 2020, foram coletados os seguintes dados:

(i) $48,45 \%$ dos entrevistados consideram que o ritmo do trabalho telepresencialaumentou, em comparação com o trabalho presencial; e

(ii) $25,05 \%$ dos participantes relataram que houve um aumento nas metas deprodutividade no período da pandemia (BRIDI et al., 2020).

$\mathrm{Na}$ mesma pesquisa, foram relatadas as seguintes dificuldades no teletrabalho: falta de contato com os colegas de trabalho: 60,55\%; mais interrupções: 54,59\%; e dificuldade em separar a vida familiar da vida profissional: 52,91\%. Também foram evidenciados os seguintes benefícios do teletrabalho: flexibilidade de horários $(69,09 \%)$, deslocamento $(66,23 \%)$ e menor preocupação com a aparência $(58,61 \%)$ (BRIDI et al., 2020).

Nesse mesmo sentido, Felippe (2018, p. 114) elenca as seguintes desvantagens e receios em relação ao trabalho remoto: (i) ausência de um coaching; (ii) perda no relacionamento social; (iii) perda de identidade empresarial; (iv) receio de não conseguir um desenvolvimento na carreira por não ser lembrado pelo seu gestor e não ter troca de aprendizado informal e espontâneo com os demais empregados.

Há ainda consequências sociais mais graves, como as anotadas por Alonso e Niy (2020, p. 179): “[...] o aumento da violência doméstica, a sobrecarga de trabalho para as mulheres nos cuidados com outras pessoas e com o lar, e as maiores dificuldades enfrentadas pelas mulheres para manter suas atividades laborais".

No mesmo sentido, pontifica a pesquisadora Dantas (2020, p. 190): "Para as mulheres da classe trabalhadora que estão em isolamento social, o teletrabalho se coloca como uma realidade dura, precária e exaustiva".

Diga-se o Fórum Brasileiro de Segurança Pública tem elaborado estudos sobre a violência contra a mulher nesse período de pandemia, restando consignado o seguinte: "Os levantamentos periódicos elaborados pelo FBSP têm mostrado, em todos os meses, aumentos nos índices de feminicídios e/ou homicídios em diversos estados" (FÓRUM BRASILEIRO DE SEGURANCA PÚBLICA, 2020, p. 2).

Há que se preocupar também com a possibilidade de desumanização do trabalho, que poderia advir de sua prestação de forma remota. Com efeito, há um grande temor de que o trabalho se transforme em mera mercadoria, dada a forma asséptica - para usar uma expressão de Bauman (BAUMAN, 2005) — como o mesmo passara a ser prestado.

Não é demais lembrar que os marcos internacionais do mundo do trabalho, do período pós-guerras mundiais, especialmente consignados na chamada Declaração de Filadélfia, deixam claro que "o trabalho não é uma mercadoria" (BRASIL, 2019, on-line). 
Nesse contexto, faz todo sentido a advertência lançada por Antunes (2020, p. 121), ao se referir às chamadas cadeias globais de valor:

Do mesmo modo que as corporações globais sabem que a força de trabalho é uma mercadoria especial (pois é a única que desencadeia o processo produtivo presente nas cadeias globais que hoje comandam o processo de criação de valor e de riqueza social), ao longo da história os capitais aprenderam bem a lidar com (e contra) o trabalho.

Fica claro o caráter manipulador, utilitarista e autoritário do capital. Assim, a sociedade deverá estar atenta para evitar que o teletrabalho promova mecanismos de alienação do trabalhador, que o reduzam a mero "recurso" da engrenagem econômica.

Ainda no cenário social, há que se que preocupar com a tendência de precarização dos postos de trabalho. Castells $(1999$, p. 484) manifesta preocupação sobre o tema:

[...] o que parece estar surgindo é a telecomutação em telecentrais, isto é, instalações com computadores em rede espalhadas nos subúrbios das áreas metropolitanas para os trabalhadores atuarem on-line com suas empresas. Com a confirmação dessas tendências, as casas não se tomariam locais de trabalho, mas a atividade de trabalho poderia espalhar-se consideravelmente pela área metropolitana, intensificando a descentralização urbana. $\mathrm{O}$ aumento do trabalho em casa também poderá resultar de uma forma de trabalho eletrônico terceirizado executado por trabalhadores temporários subcontratados mediante acordos individuais e pagos pelo volume do serviço executado em processamento da informação.

Com efeito, o teletrabalho, a depender de como seja implementado e gerido, pode ser considerado uma forma de desestruturação e precarização do mundo do trabalho (POCHMAM, 2020).

Nesse sentido, o trabalho remoto, por certo, enfraquecera ainda mais os tênues laços que ligam os trabalhadores entre si, afastando-os de seu reconhecimento como categoria profissional e classe social.

Assim, as forças progressistas da sociedade devem - máxime nesse momento de recrudescimento de políticas autoritárias - estar atentas, posto que "Se estas tendências não forem obstadas, não é difícil constatar que teremos mais informalização com informatização, que será 'justificada' pela necessidade de 'recuperação' da economia pós-Covid-19““ (ANTUNES, 2020, p. 119).

Sobre a atuação dos sindicatos no contexto do teletrabalho, colha-se o ensinamento do Juiz do Trabalho Barbosa Júnior (2020, p. 161):

Quando o uso daquelas tecnologias enseja o teletrabalho, vale dizer, o labor longe das empresas, há um isolamento ainda maior do trabalhador. Esta simples circunstância mentalmente o afasta ainda mais da esfera coletiva que engendra um sindicato.

Efetivamente, os novos paradigmas do labor estão situados fora do âmbito histórico de atuação dos sindicatos, notadamente porque este foi forjado 
ainda dentro da lógica das fábricas, onde se reuniam todos os empregados destas para desenvolver diariamente seu mister.

Os sindicatos deverão, assim, passar por um processo de depuração, cabendo-lhes adotar técnicas de atuação compatíveis com essa nova realidade do mundo do trabalho.

Diga-se, por fim, que se tem falado em determinismo tecnológico (SANTOS; JAKOBSEN, 2020, p. 22), no contexto da utilização, no mundo do trabalho, dos avanços decorrentes da chamada Revolução 4.0. Entretanto, parece que não é ocaso, posto que o uso de novas tecnologias decorre de decisões empresariais, portanto, de opções políticas. Assim, os trabalhadores poderão intervir sobre as mesmas, conformando, dentro do debate público e da pressão política, a maneira como as mesmas serão implantadas (Ibid.).

\section{Teletrabalho: aspectos administrativos}

Necessário ressaltar que o teletrabalho foi uma necessidade surgida no campo da Administração, tanto pública quando privada, com o intuito de dar continuidade ao trabalho, uma vez que o isolamento social inviabilizava a reunião e o deslocamento de trabalhadores. Entretanto, ao que parece, veio para ficar.

Nesse sentido, o professor André Miceli - coordenador do MBA em Marketing e Negócios Digitais da Fundação Getúlio Vargas — estimou, em abril de 2020, que o trabalho remoto cresceria em torno de $30 \%$ após a estabilização dos casos de Covid-19 e o retorno das atividades empresariais (UOL ECONOMIA, 2020).

Como já ressaltado, a implantação do teletrabalho advém da adoção empresarial de meios telemáticos, sendo essencial, nesse momento de transição, que o mundo empresarial tome iniciativas no sentido de atualizar seus recursos tecnológicos. Tudo sob pena de perder importantes mercados consumidores. Trata-se de verdadeira questão de sobrevivência:

Para que as empresas consigam se manter vivas é imprescindível não somente o investimento em constantes atualizações e adaptação às novas culturas, como também a utilização da criatividade para lidar com as dinâmicas mutações, dentre as quais o crescimento do trabalho em ambiente virtual, já que a globalização derrubou todas as fronteiras, com a disseminação da informação e a virtualização das atividades laborais (FELIPPE, 2018).

Além da inovação tecnológica, a entrada no mercado de trabalho de pessoas que já foram educadas com acesso ao mundo virtual demanda mudanças na forma de gerir as empresas. Esses novos profissionais, dada a sua formação ter se realizada no contexto do desenvolvimento tecnológico atual, precisam ser gerenciados de formas inovadoras, dialogais e flexíveis, sob pena do empreendimento perder recursos que venha a investir nos mesmos, haja vista a possibilidade do mercado oferecer propostas de emprego, onde haja mais empoderamento do trabalhador (Ibid.).

De olho nesse novo perfil de trabalhador, é que as empresas estão atualizando sua política de benefícios, ofertando vantagens que sejam consentâneas com o momento social que se vive, com o objetivo de "cativar" e manter seus trabalhadores. Citem-se algumas dessas iniciativas: vale-internet, terapia on-line, entrega de equipamentos ergonômicos, 
serviços de babá ou cuidador, ou mesmo a disponibilização de uma verba a ser gerida de forma flexível pelo empregado beneficiário ("vale-tudo") (DAYRELL, 2020).

Ainda no que toca à satisfação do teletrabalhador, interessante a conclusão estabelecida por Castro (2019, p. 182): "Há indícios nos resultados da pesquisa que quanto maior a flexibilidade de horário na prática de teletrabalho, maior o comprometimento normativo. Também indica que quanto melhores são os recursos de Internet e equipamentos para o teletrabalho, maior a satisfação do empregado."

A psicóloga Maria da Conceição Uvaldo assevera que “[...] as empresas devem ter um canal para ouvir as demandas dos trabalhadores e para passar informações sobre o que acontece dentro da companhia, o que pode reduzir a angústia dos funcionários - por exemplo, em relação à situação financeira da organização na crise“ (MUNIZ, 2020, on-line).

Em verdade, "Para a adequada implementação do teletrabalho e sua gestão, para além de questões ergonômicas e recursos materiais, é necessário planejamento e capacitação dos teletrabalhadores sobre como administrar o tempo, autogerenciar tarefas e conciliar trabalho-família“" (MARTINS, 2020, on-line).

\section{Teletrabalho: aspectos psicológicos}

Dadas as peculiaridades do teletrabalho, se faz necessário buscar a proteção do trabalhador de abusos que possam atingir sua dignidade e gerar malefícios à sua saúde física e psíquica, mesmo que a longo prazo (FELIPPE, 2018). Isso porque eventuais abusos contra o teletrabalhador ficarão na esfera do trato entre patrão e empregado, tornando-se invisíveis para os demais membros da vida corporativa.

Nesse sentido, há relatos de que o teletrabalho — dada a maneira abruta como fora implantando, sem treinamento e sem período de adaptação - causou impactos imprevisíveis e mesmo devastadores, do ponto de vista psíquico, levando ao esgotamento físico e mental (MUNIZ, 2020).

Confira-se o consignado em estudo sobre o tema:

[...] os trabalhadores com os maiores rendimentos passaram a atuar em esquema de home office e, por isso, sofreram diversas pressões e vivenciaram extensas jornadas de trabalho; enfrentaram ausência de contato com colegas, o que aumentou a incidência de problemas como depressão e ansiedade; tiveram sobrecarga de tarefas, com a necessidade de se dividir entre as atividades do trabalho e as domésticas, muitas relacionadas ao cuidado com os filhos, que tiveram as aulas suspensas. Em diversos casos, essas situações ocasionaram ainda conflitos familiares (AUGUSTO JÚNIOR, 2020, p. 160).

Nessa quadra, há que se citar que a implementação do trabalho remoto tem levado trabalhadores à exaustão, causando elevado esgotamento físico e mental.

Desse modo, o empregado deverá cuidar para não comprometer seu direito à desconexão, que deve ser entendido como direito ao lazer, ao convívio familiar e social e ao 
descanso reparador. Tudo sem ser interrompido por necessidades "sempre urgentes e inadiáveis" da corporação.

Trata-se de um grande desafio, posto que as pessoas, naturalmente, se veem compelidas a, todo tempo, conferir seus aparelhos telemáticos e redes sociais, oportunidade ímpar para ser acessado pelo "bondoso chefe".

Esse aspecto foi observado por Felippe (2018, p. 114): "Outro ponto de suma importância é o risco de não se conseguir desconectar do trabalho, uma vez que até mesmo em seu horário de lazer e descanso, atualmente, as pessoas estão on-line, sendo, portanto, possível contatá-las a qualquer tempo".

O teletrabalhador deve aproveitar satisfatoriamente as oportunidades de convívio social, visto que "[...] a inércia pode nos levar a ficar em casa, mas temos que nos forçar a sair nos fins de semana, ver os amigos e ter certas rotinas de esporte ou de caminhadas diárias“(JERICÓ, 2020, on-line).

Há que se dizer ainda que a atomização do trabalhador, o qual se vê distante se seus colegas de trabalho, submetendo-se integralmente às necessidades de seu patrão, vulnera sua alto-estima, sendo certo que "este sentimento de falta de pertencimento a algo mais firme mostra-se perverso, trazendo consigo uma alta instabilidade de sentimentos ao trabalhador não mais sujeito a um vínculo de emprego contínuo" (BARBOSA JÚNIOR, 2019, p. 45).

Aspecto altamente relevante diz respeito à privacidade do trabalhador, que pode ser vilipendiada pelo patrão, em um processo de vigilância que vá além do razoável. Essa situação pode se tornar ainda mais perversa e mesmo tóxica se o escrutínio das atividades do empregador se fizer sem autorização do mesmo, ou, ainda pior, sem o seu conhecimento.

Seria a instauração de uma empresa panóptica ${ }^{3}$, cabendo muito bem utilizar tal termo, tendo em vista que as relações de trabalho encerram um dos principais esquemas de relação de poder e dominação existentes na sociedade (PEGO, 2019).

Uma verdadeira sociedade da vigilância, onde "[...] tudo virou de cabeça para baixo: aquilo que para Weber, Adorno e Foucault era uma visão aterradora - a racionalidade de vigilância total do mundo administrado - , é uma promessa para os que vivem no presente" (BECK; BUENO, 2011, p. 370).

Sobre o tema, confira-se o entendimento plasmado no instigante artigo do Procurador do Trabalho Pego (2019, p. 684):

Assim como o prisioneiro, que imagina ser monitorado a cada momento, controla o seu comportamento para não ser punido, o trabalhador controla o

\footnotetext{
${ }^{3}$ Ideia formulada pelo filósofo e jurista inglês Jeremy Bentham (1748 - 1832), célebre representante do utilitarismo. Diga-se que "o Panóptico é passível de ser visto como um edifício com arquitetura e arranjos estilísticos únicos. Um prédio de disposição circular, envolto por celas perfeitamente alinhadas, perscrutadas incessantemente pelo olhar vigilante do observador assentado em uma torre central. O observador trata-se de um personagem essencial para o funcionamento completo e absoluto da ferramenta de ação utilitarista. Cada detalhe e feitio da estrutura do Panóptico, por menor e mais singelo que fosse, foi pensado, esboçado, desenhado e devidamente problematizado pelo meticuloso jurista inglês. Da localização das escadas ao posicionamento das janelas e vitrais, do ângulo de entrada da luz exterior no recinto à circunferência exata das celas, passando pelos intrincados aspectos da ventilação dos diferentes andares, nada foi esquecido ou deixado ao acaso." (TRINDADE; NUNES, 2008, p. 345).
} 
seu comportamento (mesmo quando não monitorado) para produzir sempre mais e evitar ser dispensado. Nesse modelo, não há necessidade de controle exterior, como o monitoramento do tempo (dias, horas ou jornadas praticadas). Essa parte da organização do trabalho foi transferida ao empregado, nominada de autogestão (controle interior ou programático), mas não por uma mera concessão do empregador, mas simplesmente por desnecessária ou obsoleta.

Diga-se que não se trata de questão retórica ou academicista. Ao contrário, o governo chinês, por exemplo, tem usado o conceito social de scoring para "avaliar a qualidade dos seus concidadãos" (FRAZÃO, 2021, on-line).

Com certeza, essa qualidade está muito vinculada ao cumprimento de normas e pouco relacionada à capacidade de questionamento das determinações do governo de Pequim. Assim, os algoritmos são utilizados, em verdade, para classificar os cidadãos "[...] de acordo com suas convicções políticas e o seu grau de apoio ou não a determinado governo, o que pode ser utilizado para toda sorte de discriminações e perseguições“ (FRAZÃO, 2021, on-line).

Harari (2020, on-line) manifesta profunda preocupação com o tema, dizendo que a pandemia pode ser um "divisor de águas", posto que

[...] pode normalizar a implantação de ferramentas de vigilância em massa em países que até agora as rejeitaram, mas ainda mais porque significa uma transição dramática da vigilância over the skin para under the skin".

Até então, quando seu dedo tocava a tela do smartphone e clicava em um link, o governo queria saber exatamente o que seu dedo estava clicando. Mas com o coronavírus, o foco de interesse muda. Agora o governo quer saber a temperatura de seu dedo e a pressão arterial sob sua pele.

Bauman e Bordoni (2016, p. 131) também estudam a questão do chamado "monitoramento perpétuo":

Uma imensa memória é a mesma coisa que uma memória inútil, já que só pode ser consultada em parte, correndo-se o risco de formar uma visão parcial e distorcida da realidade. Não obstante, ela tem a vantagem de manter a população em estado de alerta constante: sabendo que há monitoramento perpétuo, ninguém pode se sentir seguro; ninguém está protegido dos olhos inquiridores mesmo no interior de suas paredes. Isso cria um pan-ópitco universal, onde todos sabem que estão sendo observados, mesmo sem ver o observador, que fica oculto, discreto, silencioso, ao fundo, e totalmente mais apartado e tenaz que o guarda na prisão de Jeremy Betham.

A legislação brasileira sobre o teletrabalho é omissa quanto à temática, sendo certo que a partir de fundamentos constitucionais, bem como de preceitos insertos na Lei Geral de Proteção de Dados (BRASIL, 2020a), a vida privada do trabalhador deve ser preservada. Tudo sob pena de ofensa a direitos de personalidade do empregado a serem, inclusive, reparados judicialmente. 
Isso porque, "por mais que o trabalho dignifique o homem, quando se impõem controles que avançam sobre a sua intimidade e a sua vida privada ocorre a retirada da dignidade" (FELIPPE, 2018, p. 77).

Sobre o tema, o Ministério Público do Trabalho, através de sua Procuradoria Geral emitiu a Nota Técnica 17/2020, a qual recomenda:

9. GARANTIR o respeito ao direito de imagem e à privacidade das trabalhadoras e trabalhadores, seja por meio da orientação da realização do serviço de forma menos invasiva a esses direitos fundamentais, oferecendo a realização da prestação de serviços preferencialmente por meio de plataformas informáticas privadas, avatares, imagens padronizadas ou por modelos de transmissão on-line (BRASIL, 2020c, on-line).

Diga-se que a intrusão da privacidade do teletrabalhador poderia também se dar por terceiros, inclusive em busca de dados corporativos e mesmo dos chamados segredos industriais, tema que refoge ao escopo deste estudo.

Por fim, há que se registrar a importância de se criar, no âmbito organizacional, uma estrutura que possibilite aos trabalhadores um certo acompanhamento ocupacional, assistencial, médico e mesmo psicológico, para que bem desempenhem suas atribuições telepresenciais. Sobre o tema, cite-se o trabalho de Mishima-Santos, Sticca e Zerbini (2020, p. 15):

Diante da necessidade de adaptação rápida ao teletrabalho, a adoção das estratégias de apoio pela organização e gestores poderá minimizar os impactos negativos do teletrabalho diante da pandemia da Covid-19 para a saúde mental e física dos trabalhadores, bem como a exposição a fatores de risco psicossociais presentes no trabalho.

Faz-se necessário ainda que as organizações estejam atentas para acompanhar seus teletrabalhadores no que toca a demandas psicológicas decorrentes da Covid-19. Como explica Han (2021, on-line):

O sinistro sobre o SARS-CoV-2 é que os contagiados padecem de extremo esgotamento e abatimento. Além disso, cada vez mais se ouvem casos de pacientes que, mesmo depois de curados, continuam sofrendo graves sequelas. Uma delas é a síndrome da fadiga, que pode muito bem ser descrita com a frase quando a bateria não recarrega mais. As pessoas afetadas não são mais capazes de render nem de trabalhar. É difícil para elas até mesmo encher um copo de água. Quando caminham têm que parar constantemente, porque se sentem sufocadas. Sentem-se cadáveres vivos. Um paciente explica: "É como quando o celular só tem $4 \%$ de bateria sobrando e com esses $4 \%$ você tem que aguentar o dia todo, sem poder recarregá-lo". 
Desse modo, os setores de saúde e segurança das empresas deverão se qualificar para realizar o devido acompanhamento dos trabalhadores que apresentem sequelas da Covid-19.

Deverão cuidar inclusive para que os trabalhadores não ultrapassem a quantidade de labor que se considere saudável, posto que, muitas vezes, o teletrabalho pode implicar maior esgotamento físico e mental:

O home office também cansa, ainda mais do que trabalhar no escritório. Causa tanto cansaço principalmente porque carece de rituais e estruturas temporárias fixas. É esgotante trabalhar sozinho, passar o dia todo sentado de pijama na frente da tela do computador. Também ficamos exaustos com a falta de contatos sociais, a falta de abraços e de contato corporal com os outros. Meu livro Do desaparecimento dos rituais foi publicado na Alemanha antes da pandemia. Nele descrevo nosso presente a partir da tese do desaparecimento dos rituais. Hoje estamos perdendo as estruturas temporárias fixas, inclusive as arquiteturas temporárias, que dão estabilidade à vida. Além disso, os rituais geram uma comunidade sem comunicação, enquanto o que predomina hoje é a comunicação sem comunidade. A mídia social e a permanente encenação do ego nos esgotam porque destroem o tecido social e a comunidade (HAN, 2021, on-line).

Há ainda a tendência de "dismorfobia" — ou "videodesmorfobia" — que ocorre quando o ser humano se foca exageradamente em aspectos negativos da sua compleição e aparência física (HAN, 2021).

Em síntese, a organização deve adequar no que toca ao acompanhamento psicológico de seu quadro de empregados, avaliando constantemente os métodos adotados, para a nova realidade de teletrabalho.

\section{Teletrabalho: aspectos jurídicos}

Importante registrar que, desde 2011, a CLT prescreve, em seu art. $6^{\circ}{ }^{\circ}$, parágrafo único, que "os meios telemáticos e informatizados de comando, controle e supervisão se equiparam, para fins de subordinação jurídica, aos meios pessoais e diretos de comando, controle e supervisão do trabalho alheio" (BRASIL, 1943, on-line).

Considera-se que tal dispositivo tenha sido seminal da regulação do teletrabalho no Brasil, servindo, ademais, para normatizar as relações trabalhistas que se dão através de plataformas digitais, no contexto da chamada uberização do trabalho.

Entretanto, a regulação de forma abrangente somente veio no bojo da Reforma Trabalhista de 2017. Nesse sentido, foi incluído no Texto Consolidado o capítulo II-A, o qual trata especificamente do teletrabalho (BRASIL, 1943).

Há muitas críticas a se fazer em relação à regulação dada pela reforma. Concentrarse-á, dada a natureza do trabalho, nos aspectos que se entende fundamentais.

Diga-se, nos termos do $\S 1 .^{\circ}$ do art. 75-C da CLT, que a alteração da modalidade de prestação de labor de presencial para remoto depende de ajuste individual com o trabalhador 
(BRASIL, 1943). Critica-se a ausência de intervenção sindical no referido pacto, tendo em vista à submissão do trabalhador ao empregador, dada sua condições de subordinação.

Nessa mesma linha, é altamente criticável a hipótese do $§ 2 .^{\circ}$ do art. 75-C, o qual dispõe que a alteração do regime de trabalho remoto para trabalho presencial poderá ser realizada unilateralmente por determinação do empregador, garantindo-se prazo de transição para o empregado de 15 dias (BRASIL, 1943).

Ora, a norma, tal como foi talhada pode servir como punição velada ao empregado que, por algum motivo, tenha se comportado de forma a desagradar os interesses patronais. Cita-se, como exemplo, o trabalhador que participara de movimento paredista.

Noutro giro, ao ser revertido para o trabalho presencial, altera-se toda a dinâmica da vida do empregado, inclusive com reflexos familiares e sociais.

Por esses motivos, entende-se que a alteração somente poderia se dar com a expressa concordância do trabalhador, sugerindo-se inclusive a interveniência do ente sindical que poderia aferir a higidez da manifestação de vontade.

Há que se criticar ainda o fato da legislação, em seu art. 75-D, ter deixado o tema referente a equipamentos e despesas relativos ao teletrabalho para serem resolvidos mediante contrato individual escrito (BRASIL, 1943).

Como se sabe, nesse tipo de ajuste acaba prevalecendo a vontade do empregador, o que, na prática, transfere ao trabalhador os custos com aquisição e manutenção dos equipamentos necessários à prestação do labor telepresencial. Registre-se que o dispositivo não trata somente do mobiliário e equipamentos tecnológicos, encampando também as despesas necessárias à realização do labor, tais como energia elétrica, telefone e internet.

Esse dispositivo vai ainda contra décadas de história do direito do trabalho, o qual, com base no princípio da alteridade, tem entendido que o empregador deve suportar as despesas do empreendimento. Sobre o tema, o Ministério Público do Trabalho, através de sua Procuradoria Geral emitiu a já citada Nota Técnica 17/2020, a qual recomenda empresas, sindicatos e órgãos da administração pública, entre outras coisas, o seguinte 2020:

3. OBSERVAR os parâmetros da ergonomia, seja quanto às condições físicas ou cognitivas de trabalho (por exemplo, mobiliário e equipamentos de trabalho, postura física, conexão à rede, design das plataformas de trabalho on-line), quanto à organização do trabalho (o conteúdo das tarefas, as exigências de tempo, ritmo da atividade), e quanto às relações interpessoais no ambiente de trabalho (formatação das reuniões, transmissão das tarefas a ser executadas, feedback dos trabalhos executados), oferecendo ou reembolsando os bens necessários ao atendimento dos referidos parâmetros, nos termos da lei, bem como limitações, procedimentos e determinações dos Órgãos de Controle, tais como Tribunais de Contas no caso da Administração Pública (BRASIL, 2020c, on-line).

Com a referida recomendação deixa-se claro que eventuais adoecimentos ou acidentes de trabalho decorrentes da utilização de equipamentos inadequados poderão recair sobre o empregador, nos termos do que preceitua o art. $7^{\circ}$, XXVIII, da Constituição Federal (BRASIL, 1998). 
A propósito, o México, em dezembro de 2020, aprovou lei determinando que as empresas assumam despesas referentes à energia elétrica e internet do teletrabalhador. A mesma lei preceitua que "As empresas são obrigadas a entregar e manter os equipamentos necessários ao teletrabalho, como computadores, cadeiras ergonômicas e impressoras, entre outros (OPERAMUNDI, 2020, on-line).

Destaque-se ainda, que a medida provisória $N^{\circ}$ 927, de 22 de março de 2020 (BRASIL, 2020b, on-line), regulou o teletrabalho, como medida alternativa para enfrentamento do estado de calamidade pública e emergência de saúde pública, decorrente da Covid-19. Entretanto, tal regramento teve seu prazo de vigência encerrado no dia 19 de julho de 2020, não se incorporando à legislação nacional.

Diga-se que o teletrabalho tem sido utilizado já há algum tempo no Poder Judiciário Federal, apresentando bons resultados. A Justiça do Trabalho é pioneira, tendo implementado tal prática, a título experimental, desde fevereiro de 2012, através da Resolução Administrativa $\mathrm{N}^{\circ} 1.499$ (TRIBUNAL SUPERIOR DO TRABALHO, 2020).

Nesse compasso, faz-se importante citar a existência de norma específica sobre o tema, no âmbito do Poder Judiciário Federal. Trata-se da Resolução do Conselho Nacional de Justiça (CNJ) de $\mathrm{N}^{\circ}$ 227, de 2016, a qual fora revisada pela Resolução $\mathrm{N}^{\circ}$ 298, de 2019 (BRASIL, 2016). Diga-se ainda que o tema é regulado em diversos entes da federação, quer da Administração Direta, quer da Administração Indireta, sendo prática usual (BRIDI et al., 2020).

Sobre o tema, entende-se, na esteira do pensamento de Felippe (2018), inexplicável o fato do setor público exigir, dos trabalhadores que fazem teletrabalho, produtividade superior àquela que apresentam no trabalho presencial, posto não haver fundamento legal para tal prescrição. Ademais, a transferência para tais trabalhadores de todos os ônus relativos à configuração física do ambiente de trabalho (mobiliário e equipamentos), bem como o pagamento das despesas de telefone, internet, entre outras, não parece ser razoável.

Com efeito, a Resolução do CNJ citada assevera, em seu art. 6..$^{\circ}$ § 2. ${ }^{\circ}$, que "A meta de desempenho estipulada aos servidores em regime de teletrabalho será superior à dos servidores que executam mesma atividade nas dependências do órgão, sem comprometer a proporcionalidade e a razoabilidade, e sem embaraçar o direito ao tempo livre" (BRASIL, 2016, on-line).

Ora, não se encontra justificação plausível para a cobrança de produtividade superior àquela que se verifica no trabalho presencial. Tal exigência pode inclusive desmotivar os trabalhadores que pretendem realizar trabalho remoto.

Critica-se ainda o fato de todas as despesas advindas do trabalho telepresencial recaírem sobre o servidor público. Tal ajuste pode inclusive, como já ressaltado, acarretar comprometimentos da saúde do trabalhador, tendo em vista a possibilidade de utilização de equipamentos não ergonômicos para a realização do trabalho.

Diga-se ainda que, segundo informações do Ministério da Economia, o teletrabalho no serviço público federal gerou uma economia ao erário de $\mathrm{R} \$ 1$ bilhão, nos cinco primeiros meses de adoção. A economia se refere, entre outros, às seguintes despesas: diárias, passagens, despesas com locomoção, energia elétrica, cópias de documentos, serviços de comunicação, serviços de água e esgoto e auxílio para servidores. A título ilustrativo, cite-se que foram economizados $\mathrm{R} \$ 9,732$ milhões em serviços de cópias e reprodução de documentos (MARTELO, 2020). 
Por fim, a maior crítica à regulação brasileira reside no fato dos teletrabalhadores terem sido expressamente excluídos das normas referentes à duração do labor. Com efeito, os teletrabalhadores, no bojo da Reforma Trabalhista, foram incluídos no art. 62 da CLT, sendo assim excluídos do capítulo da CLT relativo à jornada de trabalho.

Ora, não há como comparar o teletrabalhador com as demais hipóteses do art. 62, em seus incisos I e II, tendo em vista que a lógica que prevalece, em tais casos, é a de impossibilidade fática de controle da jornada de trabalho.

Entretanto, no caso do teletrabalhador, justamente por conta dos meios telemáticos que mediam o seu trabalho, é absolutamente plausível que haja a contabilização das horas prestadas, com o pagamento das horas extraordinárias decorrentes.

Nesse sentido, colha-se ensinamento articulado em trabalho de pesquisa sobre a temática:

No que tange a jornada de trabalho entendemos haver duas possibilidades. Se o trabalho remoto não exigir horário específico para o desempenho ou as tarefas atribuídas ao empregado puderem ser realizadas quando lhe convier, sem controle do empregador quanto a jornada, não há, juridicamente, o dever de pagar horas extras, em razão da autonomia atribuída ao teletrabalhador. Por sua vez, se há horário específico para o desempenho da função e/ou fiscalização do empregador quanto a execução do trabalho, haverá incidência de horas extras, pois o empregado estará subordinado ao controle de jornada (BOMFIM; ROCHA, 2020, p. 13).

Questiona-se inclusive se a redação do novel art. 62, III, da CLT seria consentânea com o art. 7. ${ }^{\circ}$, XIV, da Constituição Federal, o qual estabelece jornada de trabalho não superior a oito horas diárias e quarenta e quatro semanais (BRASIL, 1998).

Por fim, não se pode deixar de citar que, na data de 17/12/2020, foi proposto Projeto de Lei, o qual recebeu vários aportes de colegas juízes do trabalho, estudiosos do tema, o qual propõe a alteração legislativa da CLT, no que toca ao teletrabalho, de modo a "modernizar"

— no sentido de proteger o teletrabalhador — a legislação atual, ajustando-a a parâmetros internacionais.

Trata-se do Projeto de Lei $N^{\circ}$ 5581, de 2020 (BRASIL, 2020d), o qual encampa, entre outros, os seguintes pontos: saúde física e mental do teletrabalhador, gestão do teletrabalho, acidentes de trabalhos e doenças ocupacionais, responsabilidade civil no caso de danos pessoais do teletrabalhador, privacidade e segurança das informações, educação e treinamento, ética digital e inspeção do trabalho, teletrabalho realizado por pessoas com deficiência, vítimas de violência doméstica e familiar, e idosos. Por curiosidade, cite-se que o projeto altera o citado art. 62, III, da CLT, apresentando a possibilidade de o teletrabalhador receber horas extraordinárias. 


\section{Considerações finais}

A Covid-19 causou, de fato, profundas mudanças no seio social, atingindo categorias sociais historicamente vulneráveis como mulheres e desempregados.

Como se demonstrou, todo o mundo do trabalho restou impactado, tendo se exacerbado a criação de postos de trabalho precarizados. O teletrabalho parece ser a "bola da vez" no contexto laboral, podendo sua utilização configurar, em alguns casos, uma precarização ainda maior das relações laborais.

O teletrabalho, como exposto, tem caráter multissetorial, devendo-se analisá-lo sobre os prismas sociológico, administrativo, psicológico e jurídico. Somente uma abordagem sistemática poderá permitir a compreensão do instituto, possibilitando a atuação dos atores sociais - empresários, governo, sindicatos, fiscalização do trabalho, ministério púbico, poder judiciário, entre outros — sobre o mesmo.

Conta-se que o instituto se desenvolva a partir da consideração prioritária da dignificação do trabalho humano.

Acredita-se que a pandemia possa deixar, para além da morte e sofrimento a que todos se viram submetidos, um legado positivo no que toca a práticas de trabalho e comportamentos sociais que reconheçam a importância do ser humano, contribuindo para a sua valorização.

A vacina faz acreditar que haverá um novo tempo, no qual toda essa caótica situação de pandemia tenha ficado para trás. Assim, há que se olhar para o futuro com esperança, cabendo a cada um fazer a sua parte na construção de um novo normal, onde todos (especialmente as minorias vulneráveis) sejam acolhidos e respeitados.

\section{Referências}

ALONSO, B. D.; NIY, D. Y. Nossas feridas expostas pela Covid-19: o caso das mortes maternas. In: STEFANO, D.; MENDONÇA, M. L. (org.). Direitos humanos no Brasil 2020: relatório da rede social de justiça e direitos humanos. 1. ed. São Paulo: Outras Expressões, 2020. p. $179-187$.

ANTUNES, R. Rumo à uberização do trabalho. In: STEFANO, D.; MENDONÇA, M. L. (org.). Direitos humanos no Brasil 2020: relatório da rede social de justiça e direitos humanos. 1. ed. São Paulo: Outras Expressões, 2020. p. 117 - 122.

AUGUSTO JÚNIOR, F. Os efeitos perversos da crise econômica no mercado de trabalho. In: STEFANO, D.; MENDONÇA, M. L. (org.). Direitos humanos no Brasil 2020: relatório da rede social de justiça e direitos humanos. 1. ed. São Paulo: Outras Expressões, 2020. p. 157 162.

BALTHAZAR, R. Trabalho remoto na pandemia acentua desigualdades, dizem pesquisadores. Folha de São Paulo, julho 2020. Disponível em:

https://www1.folha.uol.com. br./mercado/ 2020/07/trabalho-remoto-na-pandemia-acentuadesigualdades-dizem-pesquisadores. shtml. Acesso em: 19 de dez. de 2020. 
BARBOSA JÚNIOR, F. de A. Gig Economy e contrato de emprego: aplicabilidade da legislação trabalhista aos vínculos de trabalho da nova economia. São Paulo: LTr, 2019.

BARBOSA JÚNIOR, F. de A. O teletrabalho e os sindicatos: novos rumos para a atuação dos entes de classe nos âmbitos nacional e transnacional. Revista do Tribunal Superior do Trabalho, Lex Magister, São Paulo, v. 86, n. 2, p. 158 - 172, abr. a jun. 2020.

BAUMAN, Z. Vidas desperdiçadas. Rio de Janeiro: Jorge Zahar, 2005.

BAUMAN, Z.; BORDONI, C. Estado de Crise. 1. ed. Rio de Janeiro: Zahar, 2016.

BECK, U. O que é Globalização?: equívocos do globalismo: respostas à globalização. São Paulo: Paz e Terra, 1999.

BECK, U.; BUENO, A. Diálogo com Ulrich Beck. In: BECK, U. (org.). Sociedade de risco: rumo a uma outra modernidade. 2. ed. São Paulo: Editora 34, 2011. cap. Anexo, p. 361 376.

BOMFIM, Y. R. de S. A.; ROCHA, P. L. M. F. Os desafios na implementação e continuidade do teletrabalho pós pandemia, do Covid-19, no Brasil. Revista Eletrônica OAB/RJ, Rio de Janeiro, 2020. Disponível em: http://revistaeletronica.oabrj.org.br/?artigo=os-desafios-naimplementacao-e-continuidade-doteletrabalho-pos-pandemia-do-covid-19-no-brasil. Acesso em: 19 de dez. de 2020.

BRASIL. Decreto-lei $n^{\circ} 5.452$, de $1^{\circ}$ de maio de 1943. Presidência da República. Casa Civil. Subchefia de Assuntos Jurídicos, Brasília, 1943. Disponível em: http: //www.planalto.gov.br/ccivil_03/decreto-lei/Del5452compilado.htm. Acesso em: 13 de dez. de 2020.

BRASIL. Constituição da República Federativa do Brasil (1988). Presidência da República. Casa Civil. Subchefia de Assuntos Jurídicos, Brasília, 1998. Disponível em: http://www.planalto.gov.br/ccivil_03/constituicao/constituicao.htm. Acesso em: 6 de jul. de 2021.

BRASIL. Resolução N ${ }^{\circ}$ 227, de 15 de junho de 2016, do Conselho Nacional de Justiça. Poder Judiciário. Conselho Nacional de Justiça, Brasília, 2016. Disponível em: https://atos.cnj.jus.br/files/compilado163915202007275f1 f033339780.pdf. Acesso em: 17 de dez. de 2020.

BRASIL. Decreto $N^{\circ} 10.088$, de 5 de novembro de 2019. Presidência da República. Casa Civil. Subchefia de Assuntos Jurídicos, Brasília, 2019. Disponível em: http: //www.planalto.gov.br/ccivil_03/_ato2019-2022/2019/decreto/D10088.htm. Acesso em: 9 de jul. de 2019.

BRASIL. Lei N ${ }^{o}$ 13.709, de 14 de agosto de 2018. Lei Geral de Proteção de Dados (LGPD), 2020a. Disponível em: http://www.planalto.gov.br/ccivil_03/_ato20152018/2018/lei/L13709.htm. Acesso em: 26 de jun. de 2020. 
BRASIL. Medida provisória No 927, de 22 de março de 2020. Presidência da República. Casa Civil. Subchefia de Assuntos Jurídicos, 2020b. Disponível em: http://www.planalto.gov.br/ccivil_03/_ato2019-2022/2020/mpv/mpv927impressao.htm. Acesso em: 13 de dez. de 2020.

BRASIL. Nota Técnica 17/2020 do GT Nacional Covid-19 do GT Nanotecnologia/2020. Nota Técnica para a atuação do Ministério Público do Trabalho para a proteção da saúde e demais direitos fundamentais das trabalhadoras e dos trabalhadores em trabalho remoto ou home office, Brasília, 2020c. Disponível em: https://mpt.mp.br/pgt/noticias/nota-tecnica-n17-sobre-trabalho-remoto-gt-covid-19-e-gtnanotecnologia-2.pdf. Acesso em: 19 de dez. de 2020.

BRASIL. Projeto de Lei No 5.581, de 2020, apresentado pelo Deputado Rodrigo Agostinho (PSB/SP). Dispõe sobre o teletrabalho, realizado fora das dependências do empregador, e altera disposições da Consolidação das Leis do Trabalho (CLT), Brasília, 2020d. Disponível em: https://www.camara.leg.br/proposicoesWeb/fichadetramitacao?idProposicao=2267606.

Acesso em: 18 de dez. de 2020.

BRASIL. INSTITUTO BRASILEIRO DE GEOGRAFIA E ESTATÍSTICA. O IBGE apoiando o combate à COVID-19. 2020. On-line. Disponível em: https://covid19.ibge.gov.br/pnad-covid/. Acesso em: 13 de dez. de 2020.

BRASIL. MINISTÉRIO DA SAÚDE. Secretaria de Gestão do Trabalho e da Educação em Saúde. Organização mundial de Saúde declara pandemia do novo Coronavírus: mudança de classificação obriga países a tomarem atitudes preventivas. 2020. Disponível em: https://www.unasus.gov.br/noticia/organizacao-mundial-de-saude-declarapandemia-decoronavirus. Acesso em: 17 de jun. de 2020.

BRIDI, M. A. et al. $\mathrm{O}$ trabalho remoto/home-office no contexto da pandemiaCOVID-19. 2020. On-line. Disponível em: https://www.eco.unicamp.br/remir/images/Artigos_2020/ ARTIGO_REMIR.pdf. Acesso em: 13 de dez. de 2020.

CARBAJOSA, A. Merkel apela a cidadãos e chama coronavírus de "maior desafio desde a Segunda Guerra Mundial". 2020. El país online. Disponível em:

https://brasil.elpais.com/brasil/2020-03-18/merkel-pede-colaboracao-dos-cidadaos-diantedomaior-desafio-desde-a-segunda-guerra-mundial.html. Acesso em: 14 de maio de 2021.

CASTELLS, M. A sociedade em rede. 6. ed. São Paulo: Paz e Terra, 1999.

CASTRO, S. M. de M. Reflexos do teletrabalho no comprometimento organizacional, intenção de sair, satisfação e exaustão no trabalho (Tese de Doutorado). 2019. 207 p. Tese (Programa de pós-graduação em engenharia da produção) — Universidade Federal Fluminense, Niterói. Disponível em: https://document.onl/documents/universidade-federalfluminenseescola-de-engenharia-2019-10-01-universidade-federal.html. Acesso em: 20 de dez. de 2020. 
DANTAS, C. Mulheres na pandemia garantem a vida e o enfrentamento à violência. In: STEFANO, D.; MENDONÇA, M. L. (org.). Direitos humanos no Brasil 2020: relatório da rede social de justiça e direitos humanos. 1. ed. São Paulo: Outras Expressões, 2020. p. 189 196.

DAYRELL, M. Vale-internet ganha lugar em política de benefícios na pandemia. $\mathbf{O}$ Estado de São Paulo, São Paulo, agosto 2020. Disponível em: https://economia.estadao.com. br/blogs/radar-do-emprego/vale-internet-ganhalugarem-politica-de-beneficios-napandemia/?utm_source=estadao:whatsapp\&utm_medium=link. Acesso em: 19 de dez. de 2020.

FELIPPE, G. de C. A internet e as novas tecnologias na relação de trabalho: teletrabalho/home office e a jornada de trabalho. 2018. 121 p. Dissertação (Mestrado em Direito do Trabalho) - Pontifícia Universidade Católica. Disponível em: https://sucupira.capes.gov.br/sucupira/public/ consultas/coleta/trabalhoConclusao/viewTrabalhoConclusao.jsf?popup=true\&id_trabalho= 7636553. Acesso em: 12 de dez. de 2020.

FÓRUM BRASILEIRO DE SEGURANCA PÚBLICA. Violência doméstica durante a pandemia de Covid-19. 3. ed. São Paulo: [s.n.], 2020. Disponível em: https: //forumseguranca. org. br/wp-content/uploads/2018/05/violencia-domestica-covid-19ed03v2.pdf. Acesso em: 18 de dez. de 2020.

FRAZÃO, A. Discriminação algorítmica. GENJURÍDICO.COM.BR, 2021. Disponível em: http://genjuridico.com.br/2021/06/21/discriminacao-algoritmica/?utm_medium= push\&utm_source=push\&utm_campaign=push. Acesso em: 21 de jun. de 2021 .

HAN, B. Teletrabalho, Zoom e depressão: o filósofo Byung-Chul Han diz que exploramos a nós mesmos mais do que nunca. El país, Ediciones El País S. L., Madrid, março 2021. Disponível em: https://brasil.elpais.com/cultura/2021-03-23/teletrabalho-zoom-e-depressaoofilosofo-byung-chul-han-diz-que-nos-exploramos-mais-que-

nunca.html?event_log=fa\&prod= REGCRARTBR\&o=cerrbr. Acesso em: 20 de maio de 2021.

HARARI, Y. N. O mundo depois do coronavírus. Instituto Humanitas Unisinos online, 2020. Disponível em: https://bit.ly/3f6JDQy. Acesso em: 27 de jun. de 2020.

JERICÓ, P. Como sobreviver ao eterno home office. El País, Madrid, maio 2020. Disponível em:

https://brasil.elpais.com/brasil/2020/05/08/eps/1588958026_039677.html?id_externo_rsoc= whatsapp. Acesso em: 20 de dez. de 2020.

MARTELO, A. Home office no serviço público gerou economia de R\$ 1 bilhão em 5 meses, diz governo federal. G1, Brasília, setembro 2020. Disponível em: https://g1.globo.com/economia/noticia/2020/09/25/home-office-no-servico-publicogeroueconomia-de-r-1-bilhao-em-5-meses-diz-governo.ghtml. Acesso em: 19 de dez. de 2020. 
MARTINS, L. B. O teletrabalho e a crise da Covid-19. 2020. On-line. Disponível em:

https://www.sbpot.org.br/publicacoes/artigos//o-teletrabalho-e-a-crise-da-covid-19reflexoesa-partir-de-pontos-abordados-pela-pesquisadora-dra-gardenia-abbad. Acesso em: 13 de dez. de 2020.

MISHIMA-SANTOS, V.; STICCA, M. G.; ZERBINI, T. Teletrabalho e a pandemia da COVID-19: um guia para organizações e profissionais. Porto Alegre: Artmed, 2020.

MUNIZ, C. Home office na pandemia pode levar profissionais à exaustão: Trabalhadores somam excesso de tarefas, isolamento e cuidado com filhos. Folha de São Paulo, São Paulo, abril 2020. Disponível em: https://www1.folha.uol.com. br/sobretudo/carreiras/2020/04/home-office-napandemia-podelevar-profissionais-a-exaustao.shtml. Acesso em: 19 de dez. de 2020.

OLIVEIRA, S. Medo da pandemia de covid-19 afeta a saúde emocional: como lidar melhor. 2020. On-line. Disponível em:

https://www.uol.com. br/vivabem/noticias/redacao/2020/04/01/ medo-da-pandemia-de-covid19-afeta-a-saude-emocional-como-lidar-melhor.htm. Acesso em: 12 de dez. de 2020.

OPERAMUNDI, R. México aprova lei para que empresas paguem luz e internet de trabalhador em home office. Operamundi, dez. 2020. Disponível em: https: //operamundi.uol.com.br/permalink/67779. Acesso em: 19 de dez. de 2020.

PEGO, R. F. Trabalho remoto e o Panóptico. Revista LTr, LTr, São Paulo, v. 83, n. 6, p. 678 -685 , junho 2019.

POCHMAM, M. Os trabalhadores na regressão neoliberal. In: OLIVEIRA, M. P. D. A. (org.). A Devastação do trabalho: a classe do labor na crise da pandemia. 1. ed. Brasília: Gráfica e Editora Positiva, 2020. cap. 2, p. 31 - 53.

QUINTELA, S. Ceará tem decreto de isolamento prorrogado até 31 de maio; Fortaleza segue em 'lockdown'. Diário do Nordeste, Fortaleza, maio 2020. Disponível em:

https://diariodonordeste. verdesmares.com.br/negocios/ceara-tem-decreto-deisolamentoprorrogado-ate-31-de-maio-fortaleza-segue-em-lockdown-1.2247732. Acesso em: 13 de dez. de 2020.

SANTOS, A. H. S.; JAKOBSEN, K. A. O trabalho nas atuais transformações da globalização capitalista. In: OLIVEIRA, M. P. D. A. (org.). A Devastação do trabalho: a classe do labor na crise da pandemia. 1. ed. Brasília: Gráfica e Editora Positiva, 2020. cap. 1, p. 9 - 29.

SANTOS, B. de S. A cruel pedagogia do vírus. Coimbra: Edições Almedina S.A., 2020.

SECRETARIA DE SAÚDE DO ESTADO DO CEARÁ. Isolamento social protege você e outras pessoas do coronavírus. 2020. On-line. Disponível em: https://www.saude.ce.gov.br/ 2020/04/14/isolamento-social-protege-voce-e-outras-pessoas-do-coronavirus/. Acesso em: 13 de dez. de 2020. 
STÜRMER, G.; FINCATO, D. Teletrabalho e Covid-19. 2020. On-line. Disponível em: https://www.pucrs.br/direito/wp-content/uploads/sites/11/2020/06/2020_06_22-direitocovid19-ppgd-artigos_e_ensaios-teletrabalho_e_covid-19.pdf. Acesso em: 13 de dez. de 2020 .

TRIBUNAL SUPERIOR DO TRABALHO. Teletrabalho: O trabalho de onde você estiver. Brasília, 2020.

TRINDADE, G. G. da; NUNES, L. de L. O Panóptico/Jeremy Bentham. Problemata - Rev. Int. de Filosofia, Autêntica Editora, Belo Horizonte, v. 2, n. 1, p. 343 - 349, 2008. Disponível em: https://docplayer.com.br/52492139-Tadeu-t-org-o-panoptico-jeremybentham-2a-ed-belohorizonte-autentica-editora-2008-202-paginas.html. Acesso em: 19 de dez. de 2020.

UOL ECONOMIA. Home office deve crescer $30 \%$ no país após coronavírus, diz professor da FGV. UOL, São Paulo, 2020. Disponível em: https://economia.uol.com.br/empregosecarreiras/noticias/redacao/2020/04/06/home-office-coronavirus.htm. Acesso em: 19 de dez. de 2020. 